\title{
Self-Censorship and the Academic Mission
}

\author{
Mark Mercer
}

Sex, race, religion, Israel-Palestine, pandemic restrictions, abortion: speak your mind or even just float an idea and you might have to pay a steep price. So you hold your tongue. Self-censorship is widely practiced in university communities, under-discussed though it is. (Self-censorship is itself a topic about which people self-censor.) What to do about it?

One suggestion is that universities and professors post rules of conduct designed to facilitate free and open discussion of sensitive topics. I'm skeptical that creating and enforcing rules will help at all. Rules are good for solving coordination problems but self-censorship stems from the realities of university culture. Indeed, as I will argue, rules would likely make things worse.

"Self-censorship" can refer to any instance of holding back a comment for whatever reason. Not all occasions on which a person self-censors, then, are occasions for regret. Self-censorship is worth worrying about when people withhold comments they think would contribute positively to the discussion. They withhold them out of fear of losing friends or status or of becoming a target for hostility and ill will. Self-censorship is worth worrying about when students refrain from participating fully in a discussion because they fear bad grades or when professors clam up at meetings because they fear jeopardizing their quest for tenure, promotion, or election to an office or committee.

By “discussion," I mean, of course, engagement in colloquia and seminars and conversing with colleagues or students in formal meetings. But I'm also using the term to include talking in the hallways and cafeterias and asking questions of visiting speakers. And I am not limiting "discussion" to speaking. Both scholarly and academic publications count as discussion. Even messages or cartoons on one's office door do. When a person declines to say something (in the expanded meaning of "say") that he thinks would likely contribute to the

Mark Mercer is a professor of philosophy at Saint Mary's University, in Halifax, Nova Scotia, and the president of the Society for Academic Freedom and Scholarship. He last appeared in AQ in winter 2020 with "Why Scholars Won't Research Group Differences." 
academic purpose of the discussion because he is afraid of what might happen to him for saying it, that person is self-censoring.

Let's suppose the discussion, whether spoken or written, is directed toward figuring out how something stands. (Figuring out how things stand is one of the three central projects within academic life. The others are fashioning interpretations of things and examining the evaluative attitudes we take to things.) We think that by articulating and examining ideas about some phenomenon, we will come closer to understanding it. Articulating and examining ideas is the process in which we're engaged, and it occurs to a participant in the discussion that a particular idea or criticism would help. But that participant doesn't voice his criticism. He keeps quiet because of his fear that bringing that idea into the discussion will cost him something that matters-people's good will, say, or his social status or career prospects.

Now the idea that one keeps to oneself needn't be something one believes. Suppose it occurs to me to mention the hypothesis that when two different human populations meet, typically the males of one try to kill the other males and capture the females. I might, in fact, think that this contention is false or based on a misinterpretation of the evidence. Nonetheless, I judge that bringing that hypothesis to the attention of other participants in the discussion will assist us in figuring out how something-the populating of Eurasia, say-occurred.

I'll add, since it's rarely acknowledged, that jokes, witticisms, and offtopic comments can be useful in moving a discussion forward. Suppose that a little joke occurs to me, and I think that telling my joke will help out in some way, however small. Perhaps the two sides in our discussion are threatening to harden so that an injection of levity is timely. Or perhaps, mindful of the mimetic power of puns, I suspect a small bit of word play will impress a subtle point on everyone's memory. We might also self-censor, then, when out of fear we let slide the opportunity to get a laugh.

Finally, not all academically relevant discussion concerns academic projects alone. Sometimes we need to talk about the institutions that house our academic projects. We need to talk about the university and its structures and policies, its buildings and classrooms, the union, the journals, the faculty club, or parking. When we talk about these things, hoping to increase possibilities for academic projects, our discussions are academically relevant. If we refrain out of fear from saying something we believe would be useful, again, we are engaging in self-censorship. 
In sum, we self-censor when, out of concern for our status or career or whatever, we refrain from writing or saying something we suspect might otherwise aid us in our academic quests. Self-censorship as a problem in academic life doesn't extend to those times we hold our tongue in order not to interfere with the discussion. From an academic point of view, we should suppress our impulses when our joke would derail the discussion, when we would be hogging the conversation, or when we would be embarrassing a student. (This last case might be a matter of weighing pros and cons.)

Many of us in universities are given to self-censorship, but some of us are not. Some people seem to feel little inclination to first run what they plan to say against their fears. Let us set those who are temperamentally outspoken or curmudgeonly aside. (We will, though, good colleagues that we are, always need to ensure that academic freedom protects their careers and enables them to continue their work. And we must not shun them, even as we risk being shunned by association.)

We wish to create conditions under which people engaged in academic pursuits don't self-censor (and don't even think to self-censor). We suspect that self-censorship within a community of scholars and intellectuals will increase as commitments to the academic mission weaken and as penalties for incorrect speech become more draconian. We would do well, then, to promote among the members of our community the value of the academic enterprise and to decrease or eliminate the risks to reputation and status that currently attend saying the sort of thing that upsets or offends. How to do this?

One thing not to do is to bring rules to bear. As I've mentioned, bringing rules to bear is the solution of choice among many of us keen to facilitate open and free discussion on sensitive topics. But as Plato long ago warned, creating rules to further civility is a hopeless task, like chopping off the head of a Hydra.

To follow a rule, we have to have the rule in mind and then guide ourselves by reference to it. To lower the rate of self-censorship in our intellectual community, we do want people to behave in certain ways, preferably in ways that promote academic ends. But let us be clear that people can be encouraged to do one thing and not another in many different ways. We want to create habits of forthrightness among our colleagues and students, but instituting rules is not our only option.

A danger with instituting rules is that rule-following can be its own reward, people being the strange creatures they are. This is a problem, for when people 
follow rules for the sake of following rules, the point or intention behind the rules gets lost. Bad rules will prove hard to change since the commitment to the original justification for it has waned.

Still, for most people, if you want them to follow the rule, you cannot just announce it but must also reward them for following it or punish them for ignoring it. Yet, however dispiriting the presence of inveterate rule followers is in any human community, those who follow rules only to earn rewards or to avoid punishments can thoroughly drain an institution of time, energy, and emotion.

Here is a popular set of rules for teachers to have their students abide by: ${ }^{1}$

- $\quad$ Listen respectfully, without interrupting.

- Respect one another's views.

- $\quad$ Griticize ideas, not individuals.

- Commit to learning, not debating.

- Avoid blame and speculation.

- Avoid inflammatory language.

Following these rules will, we're told, foster a more productive discussion. Teachers are to lay out the rules at the beginning of their courses. When a student fails to follow one of them, the teacher will make this known to the student (either right away or after class). When the class goes well, the teacher will note that this was largely because the students were following the rules.

I contend that such rule-making approaches to self-censorship are getting things exactly the wrong way around. Advocates of rules have noticed a correlation, but they mistakenly take cause for effect and effect for cause. Yes, a productive discussion trying to figure something out will be a discussion in which participants listen to each other and criticize others' ideas without casting aspersions on each other. But the discussion isn't productive because the discussants are well mannered. Instead, it is because the participants are committed to the academic project of figuring something out that they appear to be well mannered.

1 Alicia L. Moore, Molly Deshaies, "Ten Tips for Facilitating Classroom Discussions on Sensitive Topics," PBS.org, originally found on the website of The Center for Research on Learning and Teaching, University of Michigan (2011). 
People committed to an end will usually employ means conducive to that end and will avoid methods that divert them from it. Successful academic discussions are generally well-mannered discussions, but they are well-mannered because they are successful, not successful because well mannered. Suppose the people involved in a discussion are committed to getting something right (or interpreting something fruitfully or evaluating it circumspectly). In that case, they will listen to each other carefully, suggest novel or creative ideas, and engage in constructive criticism, because they recognize, perhaps only implicitly, that by doing so they increase the chance of success in their project.

That people will tend to conduct themselves in ways that further the purpose of their engagement is a fairly elementary point. It's not likely that the writers of the rule books missed it. What accounts for the existence of rule books, then, seems to be that their authors don't have academic engagement in mind as the purpose of the classroom. For example, Emily Chamlee-Wright recently wrote:

The university campus is a social space just as it is an intellectual space. From faculty mentors to classmates, teammates, roommates and friends, much of the college experience is relational. Learning how to engage with others effectively is an essential part of developing one's reasoning, critical thinking, and moral imagination. In other words, we need relationships as much as we need intellectual content if we are to achieve the ultimate end of a liberal education: human flourishing. ${ }^{2}$

Rules, then, at least in Chamlee-Wright's view, are not for the sake of academic ends but for bringing students into patterns of behavior that tend toward effective engagement with others. For her, the end is not figuring something out but human flourishing. Figuring something out is an end along the way, subordinate to the higher end of flourishing.

Though she doesn't think they are ultimate ends, Chamlee-Wright accepts that academic engagement and figuring things out are ends. She does not take figuring things out to be simply a means. If we think figuring things out is simply a means to another end, we would want to evaluate it directly against its effectiveness in securing that end. If our end, human flourishing, can be achieved

2 Emily Chamlee-Wright, "Coaching Students Through The Self-Censorship Dilemma," Forbes, October 4, 2019. 
more quickly or more reliably in some other way, then we would do well to dispense with our inefficient means entirely and go with the better means. If human flourishing can be promoted through training better than through liberal study, then training it should be.

For Chamlee-Wright, liberal study is an end, but an end subordinate to that of human flourishing. As an end, we may not want to put it aside even should it prove less efficient than other means, but still it can be evaluated and reformed in light of the ultimate end. Reformations that cripple or deform liberal study might commend themselves if they promote human flourishing. On the other hand, those professors and students who value liberal study for its own sake and who do not subordinate it to a superior end will want to understand how best to engage in it and realize it in itself. They will not be moved by reforms that promise to enhance human flourishing when those reforms threaten to diminish liberal study itself.

Professors and students will self-censor less often and less severely in either of two situations. If they come to value academic engagement highly; and if speaking their minds comes to pose little risk to other things that matter to them. Speaking our minds, though, will become less risky when those in our community come to value academic engagement and value it for its own sake, rather than as primarily a means to a further end. That is because those who value academic engagement will want, above all, to contribute to the discussion as best they can.

In the end, the problem of academic self-censorship has its source in how highly participants in academic projects value academic engagement and the academic mission. How, then, our question must be, to raise the level at which students and professors value for itself the academic mission of engaging intellectually with the things of the world? I have two ideas.

First, we need to disentangle academic purposes from the various functions, however laudable, that are unreflectively included among the aims of higher education. The confusion of academic aims with social goals is ubiquitous. For example, here is a recent statement, from Lewis \& Clark College president Wim Wiewel, which innocently substitutes for the university's academic mission other, non-academic aims: “As I see it, higher education has three core purposes: to encourage lifelong exploration of the self and one's own values; to 
develop the skills needed to embark on meaningful careers; and to prepare for full, and civil, participation in public life." ${ }^{3}$

President Wiewel's three “core purposes" are not academic purposes at all but, at best, some of the desirable side effects that can accrue from liberal study. Perhaps the first is an effect that can be attained only through immersion in liberal study, though I am doubtful. The other two don't require liberal study, for they can be served in other ways. As we saw above, human flourishing is a fourth non-academic end, and another to which liberal study is only incidental.

When we assemble in a classroom or a laboratory or gather around a table or read or write or think on our own, our purpose is nothing other than to come to an understanding of the phenomenon at hand. We enjoy the processes of forming and evaluating understandings, and we enjoy contemplating the world through our understandings. That and only that is the academic purpose.

To begin disentangling the academic from that which might flow from it, we should articulate for our students and colleagues why we are gathered at a university and make clear that we are not there to prepare for jobs, impress each other, improve our manners, or save the world.

Finally, professors and students need directly and exclusively to engage in the academic projects at hand. When we participate in academic discussion, understanding it not as an exercise in self-awareness, or career preparation, or socialization, but entirely as part of the academic mission to fashion an understanding of some aspect of the world, we open a civil and collegial space in which we and our interlocutors feel free to speak their minds. This is how we defeat self-censorship.

3 Wim Wiewel, "The Case for Liberal Arts Education in a Time of Crisis," The New Republic, May 27, 2020. 